\title{
Female American mink, Mustela vison, mate multiply in a free-choice environment
}

\author{
MICHAEL D. THOM*, DAVID W. MACDONALD*, GEORGIA J. MASON†, \\ VIVI PEDERSEN \& \& PAUL J. JOHNSON* \\ *Wildlife Conservation Research Unit, Department of Zoology, University of Oxford \\ $\dagger$ Animal Behaviour Group, Department of Zoology, University of Oxford \\ $\ddagger$ Zoological Institute, University of Copenhagen \\ (Received 24 February 2003; initial acceptance 10 April 2003; \\ final acceptance 23 September 2003; MS. number: 7628R)
}

\begin{abstract}
Like most solitary carnivores, the home ranges of male American mink overlap with those of several females, but each female typically shares its range with only a single male. Nevertheless, female mink produce multiply sired litters. Unusually among mammals, the physiological characteristics of female American mink make them highly suited to multiple paternity, suggesting that polyandry in the species may result from female behaviour rather than from coercion by males. In a free-choice experiment on captive-bred animals, all female mink mated multiply, with seven of the eight mating with all three available partners. Since females sometimes resisted copulations, multiple mating in this species may result from their behaviour rather than male coercion. Females visited males nonrandomly, but visiting patterns did not predict mating patterns, suggesting disparate social and mating preferences. There was no evidence for precopulatory female choice, since the allocation of copulations among available males did not deviate significantly from the expected distribution. Females mated multiply only around the predicted times of ovulation, contrary to the expectation that they should be more selective at times of peak fertility. Larger males copulated for longer in total: copulation duration is probably under male control, suggesting that larger males could influence mating duration, perhaps increasing their share of paternity by greater sperm transfer. Our observations suggest that in wild populations, mating patterns could be influenced by female preference for multiple partners.
\end{abstract}

(C) 2004 The Association for the Study of Animal Behaviour. Published by Elsevier Ltd. All rights reserved.

Multiply sired litters have been reported in a number of mammalian groups, including rodents (Berteaux et al. 1999; Ratkiewicz \& Borkowska 2000; Wolff \& Dunlap 2002), insectivores (Stockley et al. 1993), ursids (Schenk \& Kovacs 1995) and felids (Ishida et al. 2001). Females may be polyandrous either as a result of male coercion or actively by choice. In the former case, paternity is largely determined by the outcome of intrasexual competition among males, and in the latter, females are expected to derive additional benefits from mating with multiple partners.

It is often assumed that females are relatively passive in determining the degree of polyandry in the mating system

Correspondence and present address: M. D. Thom, Animal Behaviour Group, Department of Veterinary Clinical Science, University of Liverpool, Leahurst, Neston, Cheshire CH64 7TE, U.K. (email: mthom@liv.ac.uk). D. W. Macdonald, G. J. Mason and P. J. Johnson are at the Department of Zoology, South Parks Road, Oxford OX1 3PS U.K. V. Pedersen is at the Zoological Institute, University of Copenhagen, Tagensvej 16, Copenhagen DK 2200, Denmark.
(Reynolds 1996). However, there is increasing evidence for female solicitation of multiple males, in species including rodents (Shapiro \& Dewsbury 1986; Berteaux et al. 1999), birds (Petrie et al. 1992) and fish (Evans \& Magurran 2000), although we are unaware of any experimental evidence for female solicitation of multiple males in carnivores. Because mating is costly (Daly 1976; Magnhagen 1991; Johnstone \& Keller 2000), females should choose polyandry only where this provides substantial benefits, of which many have been suggested (see reviews in Halliday \& Arnold 1987; Møller \& Birkhead 1989; Eberhard 1996; Jennions \& Petrie 1997; Birkhead \& Møller 1998; Arnqvist \& Nilsson 2000). Direct benefits to the female include stimulation of ovulation, increased litter size, access to nutrients or to male-controlled resources, bet-hedging against male infertility, replenishment of sperm stores, avoiding the costs of resisting copulation, fertilization assurance, mate retention and access to parental care (Thornhill \& Alcock 1983; Hunter et al. 1993; Sheldon 1994; Reynolds 1996; Arnqvist \& Nilsson 2000; Evans \& Magurran 2000). 
In 'resource-free' mating systems, genetic benefits may explain multiple mating; these operate either by biasing paternity towards males with 'good genes', or by increasing the genetic diversity of the litter (Andersson 1994; Reynolds 1996). In turn, good genes can increase offspring viability (Petrie 1994; Møller \& Alatalo 1999), or produce offspring with higher precopulatory (Jones et al. 1998; Wedell \& Tregenza 1999) or postcopulatory (Birkhead \& Møller 1993a; Keller \& Reeve 1995; Eberhard 1996) reproductive success.

The American mink is a seasonally breeding solitary carnivore known sometimes to mate multiply in the wild and in captivity (Enders 1952; Hatler 1976; Birks 1981). Multiple paternity has been recorded on fur farms (Shackelford 1952; Venge 1973) and in the wild (Yamaguchi 2000). However, both proximate and ultimate causes of polyandry in this species remain uncertain. In common with many solitary carnivores, mink territories overlap between, but not within, the sexes (Dunstone 1993). This type of arrangement is thought to result from differing critical resources for males and females (e.g. Macdonald 1983; Sandell 1989; Gehrt \& Fritzell 1998; Lodé 2001): food for females and access to receptive females for males. However, as expected for a species with territorial, seasonally breeding females (Emlen \& Oring 1977; Ostfeld 1990), male transience during the mating season is common in mink (Birks \& Linn 1982; Ireland 1990; Dunstone 1993) and other solitary carnivores (Erlinge \& Sandell 1986; Sandell 1989; Gehrt \& Fritzell 1999; Lodé 2001). This provides the opportunity for multiple mating by both sexes.

Mink differ from most carnivores in that females exhibit both superfecundation (multiple ova released during each ovulation) and superfoetation (multiple ovulations during the mating season leading to a single litter; Shackelford 1952; Venge 1973), meaning that polyandrous copulations both within and between ovulations can contribute to the final litter of a single mating season. Superfoetation in mink is facilitated by delayed implantation (Shackelford 1952), a phenomenon whereby fertilized blastocysts enter a state of suspended animation before implanting on the uterus. The delay in mink is unusual in being both short and variable (Venge 1973; Mead 1993; Renfree \& Shaw 2000), and it seems plausible that by enabling fertilization by multiple males, this short delay could benefit females. Thus, the physiology of female mink appears well adapted to promote fertilization of ova by multiple males, and polyandry for female benefits could potentially result. We used a free-choice apparatus to investigate three questions concerning the mating system and mate choice from the female's perspective.

First, we hypothesized that female mink would mate multiply by choice. Second, we aimed to determine whether female mink choose with regard to male phenotype. Polyandry does not preclude precopulatory choice by females (Halliday 1983), and experimental evidence suggests that polyandrous females bias matings in favour of a subset of males (Petrie et al. 1992; Horne \& Ylönen 1996; Berteaux et al. 1999). Finally, if female mink do choose their partners, which phenotypic characters do they prefer? The pronounced sexual size dimorphism of mink could be maintained by sexual selection, and as well as examining a range of other phenotypic variables, we tested whether females biased matings towards larger males. We also manipulated male familiarity, since in the wild females are likely to be more familiar with the male whose territory overlaps their own.

\section{METHODS}

\section{Study Animals}

We used captive wild-type mink from PFR Nord (Fur Animal Research Farm North), in northwest Jutland, Denmark. We used captive mink because of the difficulty of obtaining and working with sufficient numbers of wild animals. Although captive mink, including wild-type animals, may differ from wild animals in a number of ways, they provide a model for the mechanisms that could occur in natural populations. Eight female and 24 male mink were used; all were farm-reared, yearling and sexually inexperienced. We selected animals at random from the farm population, with the caveat that we aimed to minimize relatedness between females and males. Three months before the choice experiment, each female was paired with one ('familiar') male in adjacent cages in a standard farm shed. The remaining 16 males were housed in alternate cages in another part of the farm distant from the male-female pairs.

All individuals were weighed on a digital balance before being introduced to the arenas. Animals were fed standard farm feed and watered ad libitum throughout the trial. At the end of the experiment, males were returned to the farm, where they were killed for pelting, using a rising concentration of $\mathrm{CO}_{2}$. They were then immediately reweighed and several biometric measurements taken (see below). Females were returned to the general farm population to bear their litters. Number of offspring was determined for each female immediately after parturition (which occurs from late April to early May), and again in November.

\section{Experimental Design}

Eight identical experimental arenas were constructed from standard wire-mesh farm cages $(30 \times 45 \mathrm{~cm}$ and $90 \mathrm{~cm}$ high). Each comprised three contiguous cages (joined at the longest side) and a fourth attached perpendicular to these. The perpendicular cage had a smaller area in contact with the central female's cage, so solid walls were placed between all males' enclosures and the female's enclosure such that each had the same length of shared mesh. The female occupied the central cage, and the three males were in the adjoining cages (hereafter referred to as 'enclosures'). The male enclosures were termed from left to right A, B and C, so that the labels referred to enclosures in a consistent position across arenas. A wooden plate containing a hole of approximately $45 \mathrm{~mm}$ diameter was fixed between the female's enclosure and those of each of the three males. The sexual size dimorphism of mink ensured that females could enter 
males' enclosures, but males were unable to pass into the female's enclosure; we tested this in preliminary trials. There was no access between males' enclosures. Each enclosure was fitted with an external, solid-walled nestbox containing straw. Animals within nestboxes were out of sight of all other animals; however, limited visual contact between males was possible from within the cage itself.

Arenas were arranged in two groups of four, each group being housed in one of two unused farm sheds more than $100 \mathrm{~m}$ from the main farm. Arenas were suspended $10-20 \mathrm{~cm}$ above the ground to allow waste to fall through.

Both males and females were allocated randomly to arenas, with the exception of the 'familiar' male, who was allocated to the same arena as its female pair. Each of the three males in an arena was randomly allocated to one of the three peripheral enclosures A-C.

Females were introduced to the experimental arenas on 4 March 2000 for pretrial habituation to the apparatus. During this time, they had access to males' enclosures but not the males' nestboxes, which were blocked with metal doors. Females were fed ad libitum on a commercially prepared diet of offal and cereal. They received food and water only in the home enclosure. Males were introduced to their enclosures on 7 March 2000, by which time all females had visited all the enclosures in their respective arenas. The animals remained in their arenas until 25 March 2000, a total of 19 days.

Each of the eight arenas was filmed continuously from above with a black and white security camera, such that all four enclosures in each arena were in the field of view. Arenas were lit with infrared flood lamps, which remained on continuously. Infrared is outside the spectrum visible to the mammalian eye (Lythgoe 1979), so the mink were effectively in darkness during nighttime hours. The four cameras from each of the two sheds were wired through two quad processors (Appro FIO-8122) into two VCRs (Hitachi time-lapse VT-L2500E). The input was recorded at $4 \times$ time-lapse.

\section{Physical and Behavioural Measurements}

We measured the males immediately after they were killed: weight (to the nearest $0.1 \mathrm{~g}$ ), body length (from the tip of the snout to the base of the tail, $\pm 5 \mathrm{~mm}$ ), tail length ( $\pm 5 \mathrm{~mm}$ ), foot length (from the end of the calcaneum to the tip of the extended third digit excluding the claw, $\pm 0.1 \mathrm{~mm}$ ), neck circumference (immediately behind the occipital condyle, $\pm 1 \mathrm{~mm}$ ), right and left testis length and width (measured externally, $\pm 0.1 \mathrm{~mm}$ ) and canine length (from the gum line to the tip, $\pm 0.1 \mathrm{~mm}$ ). We calculated total body length (as tail + body length), and testes volume in $\mathrm{mm}^{3}$, which was the sum of the volume of each testis estimated from the formula for an ellipsoid: $\left[\left(\pi(\right.\right.$ testis length $\left.\left.) \times(\text { testis width })^{2}\right) / 6\right]$.

We transcribed female behaviour and mating events (see below) from the videos. Male mink initiate copulation by gripping the female by the scruff of the neck (Enders 1952), a behaviour hereafter termed neck biting. Copulation was defined as the male holding the female in a neck bite, with its hindlegs locked around the female or otherwise with its pelvis held against the female in a position compatible with intromission. In mink, copulation is characterized by repeated pelvic thrusting until intromission is achieved, at which point no further movement occurs (Murphy \& Douglas 1992). Determining the point at which intromission began was deemed unreliable, and as a result intromissions and ejaculations were not recorded separately. Although cameras did not have a view inside nestboxes, early observations established that nestboxes were too small to accommodate both individuals during copulation.

\section{Measures of Preference}

We calculated four types of female preference measures.

(1) Proximity (visit number and duration). Proximity is one of the simplest measures of preference, and is often assumed to be a surrogate for mating success (Andersson 1994). Measuring proximity enabled us to test explicitly whether this was the case for mink.

(2) Repeated mating (copulation number). This is a mechanism by which polyandrous females may exert paternity choice (Birkhead \& Møller 1993b; Hunter et al. 1993), since multiple ejaculations by the favoured male can devalue a competitor's sperm (Eberhard 1996).

(3) Duration of copulations achieved over the course of the experiment (total copulation duration) and per copulation bout (mean copulation duration). Increasing copulation time results in greater sperm transfer in mink (Venge 1973; Jørgensen 1985), and hence is a potential mechanism for biasing paternity towards preferred males.

(4) Likelihood of fertilization success (fertilization). Females are fertile for only the 36-48 $\mathrm{h}$ around ovulation (Johansson \& Venge 1951; Venge 1973), meaning they could manipulate paternity by favouring copulations with preferred males during this period. Ovulation in mink cannot be identified by vaginal smear tests (Hansson 1947; Sundqvist et al. 1988), so we estimated the timing of ovulation on the basis of time since first copulation. In the presence of continuing copulations, ovulation occurs every 7-8 days in mink (Hansson 1947; Johansson \& Venge 1951; Venge 1973). In captive animals, last-male fertilization precedence holds within each ovulation, with mating on the day after ovulation being optimal (Venge 1973). We thus coded each day separately for each female, beginning with its first copulation. Days of expected ovulation were coded 1 (the day of first copulation, and days 7,8 and $14,15,16$ after first copulation), the subsequent day 2 (days 2, 9, 10, 17, 18, 19), and all other days 0 . Each male's copulations were multiplied by the female's fertilization code, and summed to give an index of likelihood of success.

Because there is no evidence in the biological literature on mink to suggest which male features females are likely to prefer, we selected a range of male traits as follows.

(1) Body size and condition. Large males and those in good condition are favoured by females of many species (Andersson 1994). In captive mink, mass correlates with reproductive success (Jørgensen 1985). Mink are highly 
sexually size dimorphic, a trait that might be maintained by female choice, intrasexual competition among males, or natural selection, and female preference for large males would provide evidence for sexual selection on male size.

(2) Testis size. Across species (Harcourt et al. 1981; Stockley et al. 1997), there is a tendency for males in polygynous mating systems to have larger testes than those where intrasexual competition is rare, probably as a result of sperm competition intensity (Hosken \& Ward 2001). The sexually selected sperm hypothesis (Keller \& Reeve 1995) suggests that females might benefit from preferentially mating with males likely to be successful at sperm competition.

(3) Litter size. Offspring number is a direct measure of reproductive success, and females may choose males with high fecundity (Halliday 1983). There is some evidence for heritability of litter size in mink (Jørgensen 1985); we used the number of siblings of each male as a measure of likely future litter size. Siblings were counted at birth as part of normal farm husbandry procedures.

(4) Canine length. Canines may be important in intrasexual competition and threat displays among male carnivores (Whitehead \& Walde 1993; Gittleman \& van Valkenburgh 1997) including mustelids (Poole 1967; Erlinge 1977; although see Dayan \& Simberloff 1994). If canine size is a measure of intrasexual competitive ability among males, it could be selected by females as an indicator of male competitive ability.

(5) Familiarity. Where familiarity is an indicator of relatedness, females may avoid mating with familiar males. However, in the case of mink, a familiar male in the wild is likely to be a successful territory holder overlapping the female, and females may prefer familiar males on this basis.

In addition to measures of male success, we also analysed one aspect of male mink mating behaviour, namely the number of mating attempts by males. Neck biting is an element of mating behaviour that apparently occurs in the absence of female solicitation (Hansson 1947; Venge 1973), and appears to be lacking from the nonmating behavioural repertoire (e.g. Birks 1981). It is often assumed that female mink are unable to resist male mating attempts (although see Hansson 1947; Enders 1952), so greater mating success by males that do more neck biting might suggest a relatively passive role for females.

\section{Ethical Note}

Although the enclosures used in this experiment were small, we used the standard cages used by the farm, so that during the experiment the mink were housed in the type of cage in which they had been born and reared. Cage sizes are regulated under European Union law, and include the requirement that animals can stand fully stretched on their rear legs (hence the greater height than width). The cages also allow the animal to move about freely, to lie down fully stretched, to shelter in a nestbox and to climb the mesh. A report (SCAHAW 2001) on mink welfare produced by the EU Scientific Committee on Animal
Health and Animal Welfare concluded that small changes in cage size (such as doubling) make little difference to mink welfare.

We did not measure stress directly, apart from the assessment of stereotypies. All animals were weighed before and after the experiment; they appeared to feed and drink regularly, although males lost an average $7 \%$ of their original weight by the end of the 19-day trial (mean initial mass $2465 \mathrm{~g}$, mean final mass $2300 \mathrm{~g}$; MannWhitney $U$ test: $\left.U=692, N_{1}=N_{2}=24, P=0.03\right)$. Females maintained their mass (mean initial mass $1073 \mathrm{~g}$, mean final mass $1099 \mathrm{~g} ; U=61, N_{1}=N_{2}=8, P=0.5$ ). We also measured stereotypies in our experimental group, which in males represented $15 \pm 3 \%$ of active time. In typical farm breeding practice, females are forced into contact with a male, which often results in females stereotyping along the cage wall as far as possible from the male after mating has concluded (Mason 1993; SCAHAW 2001). We did not observe this behaviour in our experimental females; in fact, females showed virtually no stereotypies of any type.

The mink were observed closely for the first few hours of the experiment, during which time females were seen to enter each male's enclosure successfully. We checked enclosures repeatedly throughout the day, both remotely via the video cameras and directly, and they were rarely left unattended. Copulation is normally very forceful in mink; although there were some aggressive interactions, such occurrences were brief and largely ritualized (Birks 1981) and tailed off after the first $36 \mathrm{~h}$. Because the male vigorously bites the female's neck during mating, wild female mink frequently acquire neck wounds during the mating season (e.g. Venge 1973; Dunstone 1993). We checked animals for these and other injuries at least once daily. One female (F5) developed a small wound on the scruff of its neck (in accordance with the farm's normal practice, the wound was not treated.) This animal was excluded from entering males' cages for 4 of the 19 test days. No other injuries were recorded, and all animals were in good health at the end of the experiment.

\section{Data Analysis}

We tested for female preference for enclosure location (i.e. a consistent side preference) by analysing the frequency of visits and copulations in each of the enclosures $\mathrm{A}, \mathrm{B}$ and $\mathrm{C}$.

We used the Poisson variance test to assess whether males were visited and mated independently of phenotype. If females allocated matings at random to the three available males, the data should be consistent with a Poisson distribution, in which case the error mean square (MS) of the square-root-transformed response variable is expected to approximate 0.25 . If matings are unevenly distributed among males, the data will be overdispersed, and the error MS will be greater than 0.25 , whereas mating events distributed among males more evenly than expected under a Poisson model would lead to the error MS being less than 0.25 . Deviation from 0.25 can be tested statistically using a chi-square dispersion test, where 
$\chi^{2}=($ error $\mathrm{df} \times$ error MS $) / 0.25$ with degrees of freedom equal to those in the model (Grafen \& Hails 2002). Differences between females in overall visit and copulation rate were adjusted for by including female ID as a categorical variable in these models.

The female mating and activity behaviours described above, interpreted as preference indices, were tested for correlation with male morphological and behavioural measurements. Except where specified otherwise, general linear models (GLMs) of the form Preference index $=$ Female + Male trait were used to analyse female preference for male traits, with male trait being treated as continuous. Residuals from all parametric tests were tested for normality; natural log transformations were used where appropriate. Where more than one univariate test was performed on the same response variable, we used sequential Bonferroni adjustment to control for multiple tests (Rice 1989).

Because one female (F5) was excluded from the male enclosures for 4 days, means cited for this animal include only the 15 days during which it had access to males' cages. Where statistical tests were used, days 11-14 (17-20 March) were scored as missing data for F5. No mating behaviour took place on day 19 (25 March) and because the experiment ended at 1200 hours on that day, it was excluded from all variables except visit number and visit duration.

We used Minitab version 13.31 (Ryan et al. 2000) for all statistical analyses. To calculate the power of our design to detect a relation between male phenotype measures and relative mating success, we used the package GPOWER (Erdfelder et al. 1996).

\section{RESULTS}

\section{Summary of Behaviour}

There was no consistent difference between the three male enclosures $\mathrm{A}, \mathrm{B}$ and $\mathrm{C}$ on the basis of visit number (Friedman test: $\chi_{2}^{2}=2.52, P=0.284$ ) or duration $\left(\chi_{2}^{2}=0.75, P=0.687\right)$, nor did they differ in copulation number $\left(\chi_{2}^{2}=0.08, P=0.962\right)$ or total copulation duration $\left(\chi_{2}^{2}=1.75, P=0.417\right)$. We assume no systematic bias in female preference for enclosure orientation, and in the following analyses the location of each male in the test arena is ignored. However, we did not have a blank control (i.e. female behaviour in the apparatus with no males present), so we could not measure whether there were other biases in female enclosure preference.

All females mated multiply, and seven of eight mated with all three males. Females took between 1 and 11 days to mate with the maximum number of males $(\overline{\mathrm{X}} \pm \mathrm{SE}=$ $5.25 \pm 1.4$ days). On average, females mated $11.75 \pm 2.05$ times (range 6-21) over the experiment. There was a peak in mating activity 9 days after the first copulation (5/8 females mated on this day; Fig. 1), corresponding to the expected timing of the second ovulation.

There was one outlier in the copulation data: F7 mated with male 7B 17 times (mean 3.3 for all other male/female pairs) for a total of $6.6 \mathrm{~h}$ (mean $2 \mathrm{~h}$ for all other male/ female pairs) and received 90 neck bites from the same

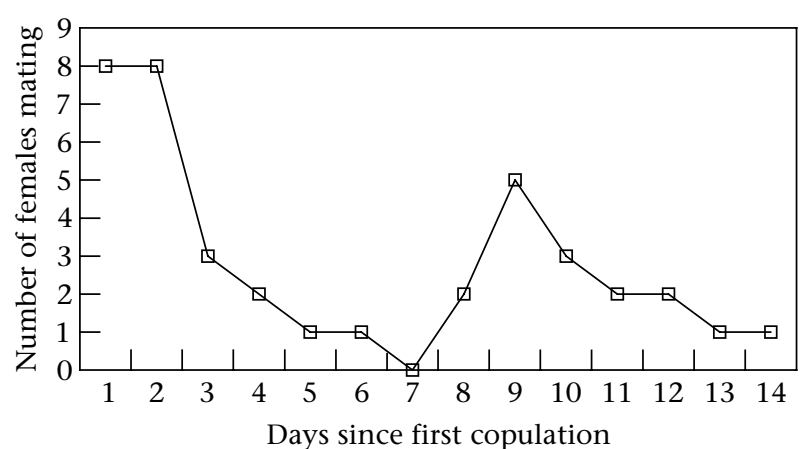

Figure 1. Number of females mating per day. All females are aligned so that the first day they mated is day 1 on the abscissa, thus, by definition all eight females mated on day 1 . No females mated on day 7 after their first copulation, and none mated after 14 days.

male (mean for all other pairs 10). Where this pair materially affected the outcome of statistical tests, we have reported the results with and without the outlier. Note that this refers only to F7's copulations with M7B; its copulations with the other two males (7A and 7C) are included in all analyses.

\section{Female Choice}

\section{Visiting and mating behaviour}

Visit number varied considerably between males, with a mean \pm SE of $51 \pm 5 \%$ to the enclosure of the mostvisited individual, followed by $26 \pm 4 \%$ and $23 \pm 3 \%$, respectively, to the remaining two males. This difference was significantly different from the expected Poisson distribution (error MS $=11.7 ; \quad \chi_{16}^{2}=748.8, \quad P<0.001$ ). This model also revealed significant differences between females $\left(F_{7,16}=9.69, P<0.001\right)$. The evidence for deviation from the expected Poisson model was much weaker for copulations. Copulation number dropped from $55 \pm$ $8 \%$ for the most successful male, to $25 \pm 4 \%$, and $20 \pm 4 \%$ for the remaining two; although this difference differed significantly from the expectations of a Poisson distribution (error MS $=0.708 ; \chi_{16}^{2}=42.5, P=0.02$ ), the effect was due to the outlier (outlier removed: error $\mathrm{MS}=0.322$; $\left.\chi_{15}^{2}=19.30, P=0.401\right)$. There is thus only weak evidence of a departure from randomness in the distribution of copulations among males.

\section{Male phenotype}

We used the male phenotype measures and the details of mating behaviour to look further for evidence of female choice.

As body size measures are expected to be highly correlated, we reduced the six indices of male size in a principal components analysis (PCA). The first two axes explained $80 \%$ of the variance, and described variance in body size and condition (decreasing mass and increasing length), respectively (Table 1 ).

No measured component of mating behaviour was predicted by either visit number or duration (Table 2), indicating that the time a female spent with a male did 
Table 1. Factor loadings for the first two components of a principal components analysis of five male size traits

\begin{tabular}{|lcc|}
\hline & $\begin{array}{c}\text { Component 1 } \\
\text { 'size' }\end{array}$ & $\begin{array}{c}\text { Component 2 } \\
\text { 'condition' }\end{array}$ \\
\hline Eigenvalue & 2.86 & 1.10 \\
Cumulative proportion & 0.571 & 0.790 \\
of variance & & \\
Variable & & \\
$\quad$ Body length & 0.728 & 0.199 \\
Tail length & 0.623 & 0.467 \\
Total length & 0.880 & 0.439 \\
Mass & 0.634 & -0.763 \\
Foot length & 0.832 & 0.029 \\
\hline
\end{tabular}

not predict that male's copulatory success. Furthermore, although the pattern of female visits to males departed significantly from random (see above), this was unrelated to male phenotype (separate GLMs of visit number, with female $1 \mathrm{D}$ as factor and male tract as covariate, all $P>0.108$ ). To investigate the power of these analyses to detect any influence of male phenotype on female choice, we used a post hoc power analysis. We used the total copulation number as the response variable, and the sample standard deviation of the slope parameter to estimate effect size. Effect size was defined (GPOWER

Table 2. Relations between female choice measures and neck bites

\begin{tabular}{|c|c|c|c|c|c|}
\hline & \multicolumn{2}{|c|}{ Visits } & \multicolumn{3}{|c|}{ Copulations } \\
\hline & Duration & Number & Number & $\begin{array}{c}\text { Total } \\
\text { duration }\end{array}$ & $\begin{array}{c}\text { Mean } \\
\text { duration }\end{array}$ \\
\hline \multicolumn{6}{|c|}{ Visit number } \\
\hline$F_{1,15}$ & $10.85^{+}$ & & & & \\
\hline$P$ & 0.005 & & & & \\
\hline \multicolumn{6}{|c|}{ Copulation number* } \\
\hline$F_{1,14}$ & $1.85^{+}$ & $0.04^{+}$ & & & \\
\hline$P$ & 0.196 & 0.826 & & & \\
\hline \multicolumn{6}{|c|}{ Total copulation duration* } \\
\hline$F_{1,14}$ & $1.17^{+}$ & $0.86^{+}$ & $1.57^{+}$ & & \\
\hline$P^{1,14}$ & 0.297 & 0.368 & 0.230 & & \\
\hline \multicolumn{6}{|c|}{ Mean copulation duration } \\
\hline$F_{1,15}$ & $0.04^{-}$ & $0.90^{+}$ & $0.93^{-}$ & $19.34^{+}$ & \\
\hline$P$ & 0.851 & 0.359 & 0.351 & 0.001 & \\
\hline \multicolumn{6}{|c|}{ Neck bites* } \\
\hline$F_{1,14}$ & $0.54^{+}$ & $0.90^{+}$ & $0.30^{+}$ & $0.52^{+}$ & $2.73^{-}$ \\
\hline$P$ & 0.473 & 0.358 & 0.594 & 0.484 & 0.121 \\
\hline
\end{tabular}

Each row was the dependent variable in a separate general linear model with female as blocking factor and each column as the independent variable. Superscripts indicate the direction of the effect.

${ }^{*}$ Outlier F7/M7B was omitted from these variables. Including the outlier produced significantly positive relations between neck bites and copulation number $\left(F_{1,15}=39.3, P<0.001\right)$, between neck bites and total copulation duration $\left(F_{1,15}=10.40, P=0.006\right)$ and between copulation number and total copulation duration $\left(F_{1,15}=17.42, P=0.001\right)$. No other result was materially affected by the outlier.
Table 3. Post hoc power analysis for male phenotype parameters predicting copulation number

\begin{tabular}{|lccc|}
\hline Predictor & $\begin{array}{c}\text { Sample } \\
\text { SD }\end{array}$ & $\begin{array}{c}\text { Slope for } \\
d=0.5 \\
\text { (power }=0.58)\end{array}$ & $\begin{array}{c}\text { Slope for } \\
d=0.7 \\
\text { (power }=0.82)\end{array}$ \\
\hline PC1 (size) & $2.35 \times 10^{-1}$ & $1.18 \times 10^{-1}$ & $1.65 \times 10^{-1}$ \\
PC2 (condition) & $4.27 \times 10^{-1}$ & $2.14 \times 10^{-1}$ & $2.99 \times 10^{-1}$ \\
$\begin{array}{l}\text { Canine length } \\
\text { (mm) }\end{array}$ & $7.30 \times 10^{-1}$ & $3.65 \times 10^{-1}$ & $5.11 \times 10^{-1}$ \\
$\begin{array}{l}\text { Testes volume } \\
\left.\text { (mm }{ }^{3}\right)\end{array}$ & $2.67 \times 10^{-4}$ & $1.87 \times 10^{-4}$ & $2.67 \times 10^{-4}$ \\
Sibling number & $2.26 \times 10^{-1}$ & $1.13 \times 10^{-1}$ & $1.58 \times 10^{-1}$ \\
\hline
\end{tabular}

'other $t$ tests' option) as the magnitude of the difference of the hypothesized population value from zero in SD units (these differences are the ' $d$ ' values in GPOWER), and using error degrees of freedom from the GLM model. We assessed the power of our tests to detect effect sizes of 0.5 and 0.7 . The calculated power values were 0.58 and 0.82 , respectively. These were translated into slopes (Table 3), which show the population rate of increase in the response necessary for an effect to be detected with the stated power.

Females spent significantly less time in the enclosures of familiar males (total time with familiar males $\pm \mathrm{SE}$ : $50 \pm 11 \mathrm{~h}$; unfamiliar: $111 \pm 19 \mathrm{~h} ; F_{1,7}=4.97, P=0.042$ ); no other aspect of female behaviour was significantly affected by male familiarity.

As noted earlier, there was a peak in mating activity at the time of the expected second ovulation (day 9; Fig. 1), and females might be expected to be more selective during fertile periods. However, of the five females that mated on day 9 , two mated with two males, and including days 8 and 10, all five females mated with at least two males (and two mated with all available partners). There thus appears to be little evidence for increased selectivity during the presumed period of the second ovulation. In fact, only on days 1, 2, 8, 9 and 10 (approximately the expected days of the first and second ovulations) did any female mate with more than one male on a single day (number of partners blocked by female: $F_{1,31}=6.84, P=0.014$ ). This indicates that, contrary to expectations, selectivity actually decreased during predicted peak periods of fertility. Overall, number of copulations, irrespective of partner number, was not significantly higher on these multiple-mating days $\left(F_{1,31}=0.131, P=0.747\right)$, indicating that female behaviour cannot be explained simply by increased overall mating activity.

Among the measures of copulation success, only duration measures were significantly associated with any phenotypic variable (Table 4). Total copulation duration was significantly positively associated with the size component score (Table 4, Fig. 2), and also with the condition component score, although this effect was eliminated after accounting for multiple tests. Mean copulation duration was not significantly correlated with either score. Thus, larger males copulated for longer in total, but there was much weaker evidence for an effect of male mass on individual bout duration. 
Table 4. Univariate analysis of the relation between male traits and mating behaviour

\begin{tabular}{|c|c|c|c|c|}
\hline \multirow[b]{2}{*}{ Male trait } & \multicolumn{3}{|c|}{ Copulations } & \multirow[b]{2}{*}{ Neck bites } \\
\hline & Number* & $\begin{array}{c}\text { Total } \\
\text { duration* }\end{array}$ & $\begin{array}{c}\text { Mean } \\
\text { duration }\end{array}$ & \\
\hline \multicolumn{5}{|l|}{ PC1 (size) } \\
\hline$F$ & $0.36^{+}$ & $10.97^{+}$ & $4.73^{+}$ & $1.70^{-}$ \\
\hline$P$ & 0.559 & 0.005 & 0.046 & 0.213 \\
\hline \multicolumn{5}{|c|}{ PC2 (condition) } \\
\hline$F$ & 0.01 & $1.40^{-}$ & $3.79^{-}$ & $6.68^{+}$ \\
\hline$P$ & 0.955 & 0.257 & 0.070 & 0.022 \\
\hline \multicolumn{5}{|c|}{ Testes volume } \\
\hline$F$ & $0.39^{+}$ & $0.63^{+}$ & $0.07^{-}$ & $0.01^{-}$ \\
\hline$P$ & 0.545 & 0.442 & 0.796 & 0.935 \\
\hline \multicolumn{5}{|c|}{ Canine length } \\
\hline$F$ & $0.61^{+}$ & $1.23^{+}$ & $0.06^{-}$ & $0.57^{+}$ \\
\hline$P$ & 0.453 & 0.294 & 0.807 & 0.470 \\
\hline \multicolumn{5}{|c|}{ Sibling number } \\
\hline$F$ & $1.31^{-}$ & $1.53^{-}$ & $0.16^{+}$ & $0.33^{-}$ \\
\hline$P$ & 0.272 & 0.236 & 0.695 & 0.557 \\
\hline
\end{tabular}

General linear models of the form Behavioural index $=$ Female + Male trait were used; the model for neck bites also included 'time in enclosure' as a covariate to control for opportunity. Superscripts indicate the direction of the effect. After column-wide sequential Bonferroni adjustment at $\alpha=0.05$, only the relation between PC1 and total copulation duration remained significant. Degrees of freedom are 1,15 for mean copulation duration and 1,14 for the other parameters.

*These variables exclude the outlier F7/M7B, a pair that mated 17 times (mean for all other pairs 3.3) for a total of $6.6 \mathrm{~h}$ (mean $2 \mathrm{~h}$ ). Including the outlier, total copulation duration was not significantly predicted by PC1 score $\left(F_{1,15}=3.31, P=0.089\right)$ and neck bites were not correlated with PC2 score $\left(F_{1,15}=1.60, P=0.225\right)$.

Because males were assigned randomly to arenas and enclosures, physical differences between males were not consistent across groups, and relative homogeneity of physical features in some sets of males could therefore

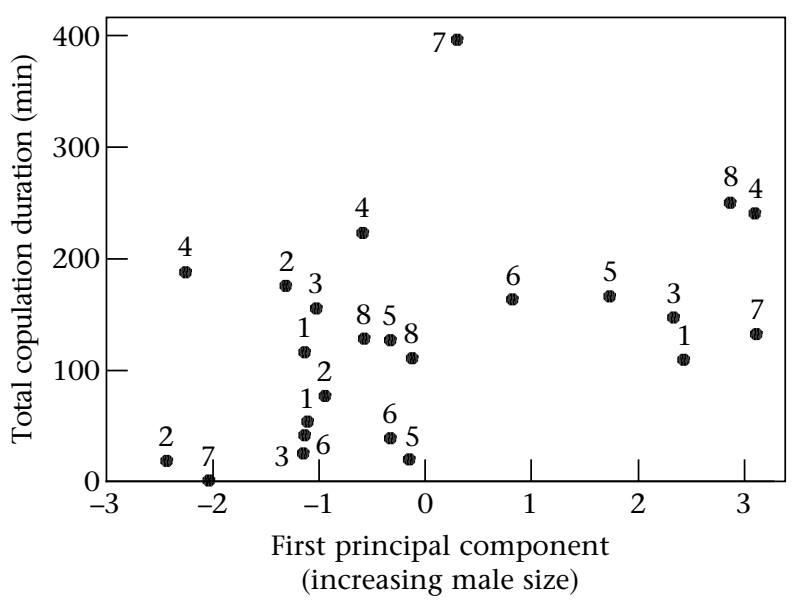

Figure 2. Copulation duration in relation to male size (as measured by PC1; see Table 1). The eight females are labelled. Excluding the outlier (female 7 at the top of the figure) and with female identity as a blocking factor, the relation is significant $(P=0.008$; outlier included: $P=0.089$ ). explain the absence of any relation between male phenotypic variables and mating success. However, variance in within-group male traits did not correlate with variance in the number of copulations of males in the group (Pearson correlation: all $\left|r_{7}\right|<0.433$, all $P>0.283)$, making this an unlikely explanation for the result. We also examined neck bites, which may influence copulation rate: males in poorer condition (principal component 2) tended to make more neck bites (Table 4; this model includes the time females spent in the male's enclosure to control for access). However, number of neck bites had no effect on copulation success (Table 2).

We found no evidence that repeated copulations directly influenced female reproductive success: there was no correlation between the number of copulations a female received (across all males) and litter size at birth (Pearson correlation: $r_{7}=0.153, P=0.718$ ) or at weaning $\left(r_{7}=0.160, P=0.704\right)$. Neither was there any correlation with the total copulation duration across all males (initial litter size: $r_{7}=-0.162, P=0.702$; litter size at weaning: $r_{7}=-0.422, P=0.297$ ).

\section{DISCUSSION}

\section{Polyandry}

All female mink mated multiply, and all but one mated with all three of the available males. This experiment was free from physical interactions among males, the predominant intrasexual component of sexual selection. Thus, our results support the hypothesis that captive female mink actively choose polyandry, rather than passively accepting the outcome of male-male competition. Although it has been proposed that wild male mink defend females during the mating season (e.g. Dunstone 1993), other authors have noted that females in captivity may allow several matings (e.g. Hansson 1947; Enders 1952). If our results hold in wild populations, it would suggest that females actively seek out multiple matings, a surprising finding given the spatial arrangement of mink populations. However, simultaneous polyandry in wildliving female mink would not exclude the possibility that males attempt to defend access to potential partners (Dunstone 1993). Female behaviour may often conflict with males' interests; for example, females in many species of socially monogamous birds seek extrapair copulations (Kempenaers et al. 1992; Graves et al. 1993; Soukup \& Thompson 1997).

We found no correlation between the number and duration of visits to males' enclosures, both of which departed significantly from random, and the males' associated mating success (measured by copulation number, copulation duration, or likelihood of fertilization success). The nonrandom visiting behaviour suggests that females differentially prefer (or avoid) contact with some males, but that this is for reasons other than mate choice. Female social preferences could, for instance, be related to factors such as the perceived risk of aggression for different males. Whatever the cause, our results emphasize that female social preference of males is not necessarily a good indicator of sexual preference, in mink as well as in 
other species (Andersson 1994, page 124). At this stage, we cannot exclude the possibility that females had idiosyncratic preferences for particular enclosures within the arena, which could equally explain the nonrandom visiting behaviour. There were, however, no consistent preferences across females for any particular enclosure position.

We found no relation between mating patterns and any of the male phenotype measures. Although this could arise because we chose the wrong male variables, the observation that females allocated matings to males in a manner not significantly different from that predicted by chance suggests that our females were not selective of mating partners. Furthermore, during periods of expected peak fertility, females were more likely to mate with multiple partners than during the remainder of the cycle, although overall copulation number was unaffected. This observation also suggests that females are relatively unselective of mating partners.

Our interpretation that polyandry in mink is driven by female behaviour relies on the assumption that females can refuse unwanted matings, since polyandry could equally arise through male coercion (Smuts \& Smuts 1993; Clutton-Brock \& Parker 1995). Although it is often suggested that female mink are effectively powerless to determine whether copulation takes place (e.g. Hansson 1947; Dunstone 1993), this was not supported by our observations. On several occasions, males were seen to attempt to initiate mating, but no copulation followed. We saw no copulations in which males subdued apparently unwilling females. Furthermore, there was no correlation between either number of neck bites or time spent in a male's enclosure and copulation number, indicating that neither males with a high attempted mating rate nor those in frequent contact with females were more likely to achieve matings. Enders (1952, page 721) also believed that on some occasions 'the female may resist the male', stating that mink farmers use physical restraints and even whisky to subdue females that repeatedly fight off males. Finally, despite having the opportunity to avoid males by remaining in their home cage in our experiment, females entered males' enclosures many hundreds of times during the experiment, and mated frequently. In the experimental conditions used here, females were readily able to escape the males' attentions by returning to their enclosure. In the wild, it is possible that females would be unable to escape so easily, and forced copulations by males may be more frequent in a wild setting.

We recognize the possibility that the captive-bred animals we used could be a relatively poor model for wild populations. Although we used wild-type animals, which physically closely resemble wild mink, they have none the less been subject to artificial selection for many generations. In particular, captive breeding can have the effect of selecting for individuals with high mating capacity and low partner discrimination. Nevertheless, our results, even if they pertain only to captive-bred stock, indicate that polyandry can be selected for in this species, and could thus occur in wild populations. Our results are also relevant to the feral populations that are now present in many parts of the world, and are known to mate multiply in the U.K. (Yamaguchi 2000). Our data do not enable us to determine what drives polyandry in captive-bred mink. However, the absence of precopulatory choice, increased levels of polyandry during periods of peak female fertility, and the absence of a relation between copulation rate and litter size are all compatible with multimale mating for postcopulatory benefits. Further work is required to determine the benefits females accrue through polyandry.

\section{Male Behaviour}

Larger males mated for longer in total, although there was no significant effect of size on copulation number. While this could reflect female preference for larger males, expressed by allowing longer copulations to larger animals, this seems unlikely to us. Since females appeared unable to terminate copulations, we believe this variable is more likely to be under male control. Size did not influence a male's ability to achieve copulations (since there was no effect of size on copulation number); nevertheless, our observations suggest that large males prefer longer copulations. This could be either because the duration achieved by small males is suboptimal, but for some reason they are unable to sustain longer copulations, or that tactics are size dependent. Since copulation duration is correlated with ejaculation number in mink (Venge 1973; Jørgensen 1985), longer copulations should benefit males by increasing the quantity of sperm transferred. However, whether any such benefit holds at the extremely long durations recorded here remains uncertain. The relation between copulation duration and relative paternity needs to be identified before the question of why larger males mate for longer can be resolved.

\section{Acknowledgments}

For valuable comments and suggestions on the manuscript, we thank Tim Birkhead, Sandra Baker, Ruth Cox, Michael Jennions and three anonymous referees. Our grateful thanks also to Leif Lau Jeppesen and Tine Simonsen of the Zoological Institute, University of Copenhagen, for their generous support and technical assistance. M.D.T. was supported by an Oxford Overseas Bursary, the ORS scheme, and Brasenose College continuation and travel grants, D.W.M. and P.J.J. by the Peoples Trust for Endangered Species and G.J.M. by the BBSRC. Use of facilities at PFR Nord was possible owing to the kind support of the Danish Fur Breeders Association.

\section{References}

Andersson, M. 1994. Sexual Selection. Princeton, New Jersey: Princeton University Press.

Arnqvist, G. \& Nilsson, T. 2000. The evolution of polyandry: multiple mating and female fitness in insects. Animal Behaviour, 60, 145-164.

Berteaux, D., Bety, J., Rengifo, E. \& Bergeron, J. M. 1999. Multiple paternity in meadow voles (Microtus pennsylvanicus): investigating 
the role of the female. Behavioral Ecology and Sociobiology, 45 283-291.

Birkhead, T. R. \& Møller, A. P. 1993a. Female control of paternity. Trends in Ecology and Evolution, 8, 100-104.

Birkhead, T. R. \& Møller, A. P. 1993b. Sexual selection and the temporal separation of reproductive events: sperm storage data from reptiles, birds and mammals. Biological Journal of the Linnean Society, 50, 295-311.

Birkhead, T. R. \& Møller, A. P. 1998. Sperm Competition and Sexual Selection. London: Academic Press.

Birks, J. D. S. 1981. Home range and territorial behaviour of the feral mink (Mustela vison Schreber) in Devon. Ph.D. thesis, University of Exeter.

Birks, J. D. S. \& Linn, I. J. 1982. Studies of home range of the feral mink, Mustela vison. Symposia of the Zoological Society of London, 49, 231-257.

Clutton-Brock, T. H. \& Parker, G. A. 1995. Sexual coercion in animal societies. Animal Behaviour, 49, 1345-1365.

Daly, M. 1976. The cost of mating. American Naturalist, 112, 771-774

Dayan, T. \& Simberloff, D. 1994. Character displacement, sexual dimorphism, and morphological variation among British and Irish mustelids. Ecology, 75, 1063-1073.

Dunstone, N. 1993. The Mink. London: T. \& A. D. Poyser.

Eberhard, W. G. 1996. Female Control: Sexual Selection by Cryptic Female Choice. Princeton, New Jersey: Princeton University Press.

Emlen, S. T. \& Oring, L. W. 1977. Ecology, sexual selection, and the evolution of mating systems. Science, 197, 215-223.

Enders, R. K. 1952. Reproduction in the mink (Mustela vison). Proceedings of the American Philosophical Society, 96, 691-755.

Erdfelder, E., Faul, F. \& Buchner, A. 1996. GPOWER: a general power analysis program. Behavior Research Methods, Instruments, and Computers, 28, 1-11.

Erlinge, S. 1977. Agonistic behaviour and dominance in stoats (Mustela erminea L.). Zeitschrift für Tierpsychologie, 44, 375-388.

Erlinge, S. \& Sandell, M. 1986. Seasonal changes in the social organization of male stoats, Mustela erminea: an effect of shifts between two decisive resources. Oikos, 47, 57-62.

Evans, J. P. \& Magurran, A. E. 2000. Multiple benefits of multiple mating in guppies. Proceedings of the National Academy of Sciences, U.S.A., 97, 10074-10076.

Gehrt, S. D. \& Fritzell, E. K. 1998. Resource distribution, female home range dispersion and male spatial interactions: group structure in a solitary carnivore. Animal Behaviour, 55, 1211-1227.

Gehrt, S. D. \& Fritzell, E. K. 1999. Behavioural aspects of the raccoon mating system: determinants of consortship success. Animal Behaviour, 57, 593-601.

Gittleman, J. L. \& van Valkenburgh, B. 1997. Sexual dimorphism in the canines and skulls of carnivores: effects of size, phylogeny, and behavioural ecology. Journal of Zoology, 242, 97-117.

Grafen, A. \& Hails, R. 2002. Modern Statistics for the Life Sciences. Oxford: Oxford University Press.

Graves, J., Ortega-Rauno, J. \& Slater, P. J. B. 1993. Extra-pair copulations and paternity in shags: do females choose better males? Proceedings of the Royal Society of London, Series B, 253, 3-7.

Halliday, T. R. 1983. The study of mate choice. In: Mate Choice (Ed. by P. Bateson), pp. 3-32. Cambridge: Cambridge University Press.

Halliday, T. \& Arnold, S. J. 1987. Multiple mating by females: a perspective from quantitative genetics. Animal Behaviour, 35 939-941.

Hansson, A. 1947. The physiology of reproduction in mink (Mustela vison Schreber) with special reference to delayed implantation. Acta Zoologica, 28, 1-136.
Harcourt, A. H., Harvey, P. H., Larson, S. G. \& Short, R. V. 1981. Testis weight, body weight and breeding system in primates. Nature, 293, 55-57.

Hatler, D. F. 1976. The coastal mink on Vancouver island. Ph.D. thesis, University of British Columbia.

Horne, T. J. \& Ylönen, H. 1996. Female bank voles (Clethrionomys glareolus) prefer dominant males; but what if there is no choice? Behavioral Ecology and Sociobiology, 38, 401-405.

Hosken, D. J. \& Ward, P. I. 2001. Experimental evidence for testis size evolution via sperm competition. Ecology Letters, 4, 10-13.

Hunter, F. M., Petrie, M., Otronen, M., Birkhead, T. \& Møller, A. P. 1993. Why do females copulate repeatedly with one male? Trends in Ecology and Evolution, 8, 21-26.

Ireland, M. C. 1990. The behaviour and ecology of the American mink Mustela vison (Schreber) in a coastal habitat. Ph.D. thesis, University of Durham.

Ishida, Y., Yahara, T., Kasuya, E. \& Yamane, A. 2001. Female control of paternity during copulation: inbreeding avoidance in feral cats. Behaviour, 138, 235-250.

Jennions, M. D. \& Petrie, M. 1997. Variation in mate choice and mating preferences: a review of causes and consequences. Biological Reviews, 72, 283-327.

Johansson, I. \& Venge, O. 1951. Relation of the mating interval to the occurrence of superfetation in the mink. Acta Zoologica, 32, 255-258.

Johnstone, R. A. \& Keller, L. 2000. How males can gain by harming their mates. Sexual conflict, sexual toxins and the cost of mating. American Naturalist, 156, 368-377.

Jones, T. M., Quinnell, R. J. \& Balmford, A. 1998. Fisherian flies: benefits of female choice in a lekking sandfly. Proceedings of the Royal Society of London, Series B, 265, 1651-1657.

Jørgensen, G. 1985. Mink Production. Hillerød, Denmark: Scientifur.

Keller, L. \& Reeve, K. 1995. Why do females mate with multiple males? The sexually selected sperm hypothesis. Advances in the Study of Behavior, 24, 291-315.

Kempenaers, B., Verheyen, G. R., Van der Broeck, M., Burke, T., Van Broeckhoven, C. \& Dhont, A. A. 1992. Extra-pair paternity results from female preference for high quality males in the blue tit. Nature, 357, 494-496.

Lodé, T. 2001. Mating system and genetic variance in a polygynous mustelid, the European polecat. Genes and Genetic Systems, 76, 221-227.

Lythgoe, J. N. 1979. The Ecology of Vision. Oxford: Clarendon Press.

Macdonald, D. W. 1983. The ecology of carnivore social behaviour. Nature, 301, 379-384.

Magnhagen, C. 1991. Predation risk as a cost of reproduction. Trends in Ecology and Evolution, 6, 183-186.

Mason, G. J. 1993. Age and context affect the stereotypies of caged mink. Behaviour, 127, 191-229.

Mead, R. A. 1993. Embryonic diapause in vertebrates. Journal of Experimental Zoology, 266, 629-641.

Møller, A. P. \& Alatalo, R. V. 1999. Good-genes effects in sexual selection. Proceedings of the Royal Society of London, Series B, 266, 85-91.

Møller, A. P. \& Birkhead, T. R. 1989. Copulation behavior in mammals: evidence that sperm competition is widespread. Biological Journal of the Linnean Society, 38, 119-132.

Murphy, B. D. \& Douglas, D. A. 1992. Reproduction in female mink. In: Reproduction in Carnivorous Furbearing Animals (Ed. by A.-H.Tauson \& M. Valtonen), pp. 39-49. Copenhagen: Nordiske Jordbrugsforskeres Forening.

Ostfeld, R. 1990. The ecology of territoriality in small mammals. Trends in Ecology and Evolution, 5, 411-415. 
Petrie, M. 1994. Improved growth and survival of offspring of peacocks with more elaborate trains. Nature, 371, 598-599.

Petrie, M., Hall, M., Halliday, T., Budgey, H. \& Pierpoint, C. 1992. Multiple mating in a lekking bird: why do peahens mate with more than one male and with the same male more than once? Behavioral Ecology and Sociobiology, 31, 349-358.

Poole, T. B. 1967. Aspects of aggressive behaviour in polecats. Zeitschrift für Tierpsychologie, 24, 351-369.

Ratkiewicz, M. \& Borkowska, A. 2000. Multiple paternity in the bank vole (Clethrionomys glareolus): field and experimental data. Zeitschrift für Säugetierkunde, 65, 6-14.

Renfree, M. B. \& Shaw, G. 2000. Diapause. Annual Review of Physiology, 62, 353-375.

Reynolds, J. D. 1996. Animal breeding systems. Trends in Ecology and Evolution, 11, 68-72.

Rice, W. R. 1989. Analyzing tables of statistical tests. Evolution, 43, 223-225.

Ryan, B. F., Joiner, B. L. \& Ryan, T., Jr. 2000. Minitab Handbook, 4th edn. Boston: Duxbury.

Sandell, M. 1989. The mating tactics and spacing patterns of solitary carnivores. In: Carnivore Behavior, Ecology, and Evolution. Vol. 1 (Ed. by J. L. Gittleman), pp. 164-182. Ithaca, New York: Cornell University Press.

SCAHAW. 2001. The Welfare of Animals Kept for Fur Production. Report of the Scientific Committee on Animal Health and Animal Welfare. http://www.europa.eu.int/comm/food/fs/sc/scah/out67_en. pdf

Schenk, A. \& Kovacs, K. M. 1995. Multiple mating between black bears revealed by DNA fingerprinting. Animal Behaviour, 50, 1483-1490.

Shackelford, R. M. 1952. Superfetation in the ranch mink. American Naturalist, 86, 311-319.

Shapiro, L. E. \& Dewsbury, D. A. 1986. Male dominance, female choice and male copulatory behavior in two species of voles (Microtus ochrogaster and Microtus montanus). Behavioral Ecology and Sociobiology, 18, 267-274.
Sheldon, B. C. 1994. Male phenotype, fertility, and the pursuit of extra-pair copulations by female birds. Proceedings of the Royal Society of London, Series B, 257, 25-30.

Smuts, B. B. \& Smuts, R. W. 1993. Male aggression and sexual coercion of females in nonhuman primates and other mammals: evidence and theoretical implications. Advances in the Study of Behavior, 22, 1-63.

Soukup, S. S. \& Thompson, C. F. 1997. Social mating system affects the frequency of extra-pair paternity in house wrens. Animal Behaviour, 54, 1089-1105.

Stockley, P., Searle, J. B., Macdonald, D. W. \& Jones, C. S. 1993. Female multiple mating behaviour in the common shrew as a strategy to reduce inbreeding. Proceedings of the Royal Society of London, Series B, 254, 173-179.

Stockley, P., Gage, M. J. G., Parker, G. A. \& Møller, A. P. 1997. Sperm competition in fishes: the evolution of testis size and ejaculate characteristics. American Naturalist, 149, 933-954.

Sundqvist, C., Ellis, L. C. \& Bartke, A. 1988. Reproductive endocrinology of the mink (Mustela vison). Endocrine Reviews, 9, 247-266.

Thornhill, R. \& Alcock, J. 1983. The Evolution of Insect Mating Systems. Cambridge, Massachusetts: Harvard University Press.

Venge, O. 1973. Reproduction in the mink. Den Kongelige Veterincere Landbohøjskole, Årsskrift, 1973, 95-146.

Wedell, N. \& Tregenza, T. 1999. Successful fathers sire successful sons. Evolution, 53, 620-625.

Whitehead, H. \& Walde, S. J. 1993. Territoriality and the evolution of character displacement and sexual dimorphism. Ethology, Ecology and Evolution, 5, 303-318.

Wolff, J. O. \& Dunlap, A. S. 2002. Multi-male mating, probability of conception, and litter size in the prairie vole (Microtus ochrogaster). Behavioural Processes, 58, 105-110.

Yamaguchi, N. 2000. The basic ecology and the reproductive biology of feral American mink in the upper Thames. Ph.D. thesis, University of Oxford. 